\title{
Improved communication between ambulance personnel and supervising doctors. A quality improvement project in central Norway
}

\author{
Trine Landsem* and Sven E Gisvold
}

Address: St. Olavs University Hospital. Department of Prehospital Medicine, Trondheim, Norway

Email: Trine Landsem* - trine.landsem@stolav.no

* Corresponding author

from Scandinavian Update on Trauma, Resuscitation and Emergency Medicine 2009

Stavanger, Norway. $23-25$ April 2009

Published: 28 August 2009

Scandinavian Journal of Trauma, Resuscitation and Emergency Medicine 2009, I7(Suppl 3):O6 doi:10.II86/I757-724I-I7-S3-O6

This abstract is available from: http://www.sjtrem.com/content/I7/S3/O6

(C) 2009 Landsem and Gisvold; licensee BioMed Central Ltd.

\section{Introduction}

In our county, we have approx 25000 ambulance missions annually, including 7200 acute emergencies. Due to organisational changes in the whole country, the Ambulance Personnel (AP) are almost always first on the scene, and usually have to act alone. It is therefore imperative that we follow them up closely, providing support and continuous education. Herein we describe our latest quality improvement efforts in this regard.

\section{Methods}

After every case of cardiorespiratory arrest, the APs send an e-mail to the supervising anaesthesiologist at the hospital. We call back as soon as possible, discuss every aspect of the case, and review the treatment on scene and during transport, making sure that no info is lost and the Utsteinform is filled in correctly. Our hope is that these contacts will be perceived as stimulating and educational and will have a general positive effect on their work.

\section{Results}

During 4 months, we have made more than 50 phone calls to APs.

Carrying out advanced medical procedures and documentation is a major challenge for the APs. The feeling of being alone can be overwhelming. Our impression so far, based on their feedback, is that this communication sys- tem is valuable and important. They feel that their work is appreciated and find the discussions to be educational.

\section{Conclusion}

The close communication between the ambulance personnel and the emergency doctors can contribute to better on scene treatment, documentation, and education. Background data for doing clinical investigations will also hopefully improve. 